\title{
Comment on A. Ghemigian, et al Familial isolated primary hyperparathyroidism due to HRPT2 mutation
}

\author{
Emmanouela Papadaki
}

Department of Nuclear Medicine, Heraklion University Hospital, Crete, Greece

\section{Dear Editor,}

In a recent article, three case reports of familiar isolated primary hyperparathyroidism due to HRPT 2 mutation are presented. ${ }^{1}$ For the detection the authors used laboratory tests, $\mathrm{u} / \mathrm{s}$ and nuclear medicine imaging techniques. In all cases they report that technetium scintigraphy was positive for parathyroid adenoma.

However, the term "technetium scintigraphy" is not a correct expression. Technetium [ $\left.{ }^{99 \mathrm{~m}} \mathrm{Tc}\right]$ scintigraphy (with free ${ }^{99 \mathrm{~m}} \mathrm{Tc}$ - pertechnetate) is used only for thyroid gland imaging.

I would like to comment that parathyroid scanning is performed with a lipophilic cationic complex of ${ }^{99 \mathrm{~m} T c}$, called sestamibi, and not free technetium pertechnetate, as is described in the article. According to the guidelines, ${ }^{2}$ dual phase ${ }^{99 \mathrm{~m}} \mathrm{Tc}$-sestamibi scans are commonly used for preoperative localization of parathyroid adenomas. Hyperactive parathyroid cells have a high concentration of sestamibi and accumulate more radiopharmaceutical, visualized in early images, 10-15 min post injection. Parathyroid adenomas usually show slower washout compared to normal thyroid gland, visualized as retention of sestamibi in delayed

Address for correspondence:

Emmanouela Papadaki, Department of Nuclear Medicine,

Heraklion University Hospital, POBox 1352 ,

Voutes-Stavrakia, 71110 Heraklion, Crete, Greece

e-mail: empapad@hotmail.com

Received 14-11-2013, Accepted 02-12-2013 images, $2 \mathrm{~h}$ p.i. (possibly due to mitochondrial binding or reduced PgP expression). However, some lesions $(10 \%-15 \%)$ will show washout of tracer by $2 \mathrm{~h}$ that is as fast as that from the thyroid. Many hyperplastic glands show such a rapid washout. Washout of tracer from adenomas is variable. ${ }^{3}$ Besides, some thyroid nodules could also accumulate and retain sestamibi. This is why dual phase sestamibi scintigraphy is often combined with thyroid scan (which is performed with free ${ }^{99 \mathrm{~m}} \mathrm{Tc}$ - pertechnetate) for differential diagnosis, especially in the case of hyperfunctioning parathyroid tissue very close to the thyroid gland or intrathyroidal adenoma. The distributions of the two tracers can be visually compared and, afterwards, the thyroid scan can be digitally subtracted from the parathyroid scan to remove the thyroid activity and enhance the visualization of parathyroid tissue. Comparison of the two scans with image subtraction procedures may increase the study sensitivity. ${ }^{2}$

In addition, image 3 (p. 456) ${ }^{1}$ is not a technetium scan but a ${ }^{99 \mathrm{~m}} \mathrm{Tc}$-sestamibi scan, because myocardium, as well as liver, are depicted. Normally, these two structures do not take up technetium pertechnetate but its complex with substances, such as sestamibi or tetrofosmin. Moreover, this image represents only early phase and not dual phase scintigraphy.

Taking into consideration the inaccurate use of the above term, it is noteworthy that several case reports have been published of parathyroid adenomas which take up not only ${ }^{99 \mathrm{~m}} \mathrm{Tc}$-sestamibi in parathyroid scin- 
tigraphy but also ${ }^{99 m} \mathrm{Tc}$ - pertechnetate during thyroid scintigraphy. ${ }^{4-7}$ The mechanism of ${ }^{99 \mathrm{~m}} \mathrm{Tc}$ - pertechnetate localization in the parathyroid remains uncertain. Hypervascularity is the most cited explanation since there is no known cellular mechanism by which parathyroid tissue could actively trap technetium, which is an iodine analogue. ${ }^{6,7}$ Other possibilities that have been proposed are the presence of a fibrous capsule around the tumor and intratumoral hemorrhage.

\section{REFERENCES}

1. Ghemigian A, Ghemigian M, Popescu I, et al, 2013 Familial isolated primary hyperparathyroidism due to HRPT2 mutation. Hormones (Athens) 12: 454-460.

2. Hindié E, Ugur Ö, Fuster D, et al, 2009, 2009 EANM parathyroid guidelines. Eur J Nucl Med Mol Imaging 36: 1201-1216.

3. Greenspan BS, Dillehay G, Intenzo C, et al, 2012 SNM Practice Guideline for Parathyroid Scintigraphy. The Journal of Nuclear Medicine Technology 40: 111-118.

4. Francini A, Emmolob I, et al, 2010, A Potential Pitfall in Parathyroid Scintigraphy: Description of A Rare Case. J Med Cases 1: 77-80.

5. Leslie WD, Riese KT, Guzman R, Dupont JO, Peterdy AE, 1996 Technetium-99m-Pertechnetate Uptake by Intrathyroidal Parathyroid Adenoma. The Journal of Nuclear Medicine 37: 861-862.

6. Kiratli PO, Peksoy I, Erba̧s B, Gedikoğlu G, Karabulut N, $1999{ }^{99 m}$ Tc- pertechnetate uptake in ectopic parathyroid adenoma. Annals of Nuclear Medicine 13: 113-115.

7. Toru Kikuchi, Hajime Watanobe, Suda T, et al, 2001 Marked Uptake of Technetium-99m Pertechnetate by Parathyroid Adenoma. Internal Medicine 40: 506-509. 